\title{
Trends in the classical biological control of insect pests by insects: an update of the BIOCAT database
}

\author{
Matthew J. W. Cock $\cdot$ Sean T. Murphy $\cdot$ Moses T. K. Kairo • \\ Emma Thompson • Rebecca J. Murphy $\cdot$ Antonio W. Francis
}

Received: 9 November 2015/ Accepted: 20 February 2016/Published online: 26 February 2016

(C) The Author(s) 2016. This article is published with open access at Springerlink.com

\begin{abstract}
The BIOCAT database of introductions of insect biological control agents for the control of insect pests was updated to the end of 2010 to include 6158 introductions, using 2384 different insect biological control agents against 588 pest species in 148 countries. Of the introductions, 2007 (32.6\%) led to establishment, and $620(10.1 \%)$ resulted in satisfactory control being reported against $172(29.3 \%)$ different pest species. The number of introductions has decreased each decade since the 1970s, but in the same period a higher proportion of introductions became established and contributed to successful control of target pests, and the number of countries implementing classical biological control increased. These positive trends reflect the greater research effort now
\end{abstract}

Handling Editor: Patrick De Clercq.

Electronic supplementary material The online version of this article (doi:10.1007/s10526-016-9726-3) contains supplementary material, which is available to authorized users.

M. J. W. Cock $(\bowtie) \cdot$ S. T. Murphy · E. Thompson ·

R. J. Murphy

CABI, Bakeham Lane, Egham, Surrey TW20 9TY, UK

e-mail: m.cock@cabi.org

S. T. Murphy

e-mail: s.murphy@cabi.org

E. Thompson

e-mail: e.thompson@cabi.org

R. J. Murphy

e-mail: r.murphy@cabi.org made to optimize the chances of successful outcomes and increased confidence in classical biological control as a viable pest management strategy against a backdrop of a risk-averse culture that has developed in some key countries in recent years.

Keywords History · Biological control agent · Introductions $\cdot$ Establishment $\cdot$ Success

\section{Introduction}

Classical biological control (CBC, not to be confused with conservation biological control) of alien insect pests by the deliberate introduction of insect natural enemies continues to be a powerful pest management tool, especially now that invasive insect pests along with other pest species are on the increase through global trade and travel (Bebber et al. 2014). However,

\footnotetext{
M. T. K. Kairo

School of Agricultural and Natural Sciences, University of Maryland Eastern Shore, Suite 3055, Richard A. Hazel Hall, Princess Anne, MD 21853, USA

e-mail: mkairo@umes.edu

A. W. Francis

Florida Department of Agriculture and Consumer

Services, Division of Plant Industry, Bureau of Methods

Development \& Biocontrol, 2725 S. Binion Road,

Apopka, FL 32703, USA

e-mail: antonio.francis@freshfromflorida.com
} 
understanding the factors that lead to successful outcomes continues to challenge researchers and practitioners. There has been much previous effort to improve predictability. In the case of insect parasitoids used as biological control agents (BCAs), significant strides have been made in the strengthening of the ecological basis of $\mathrm{CBC}$, mainly through the identification of the broad negative relation between the extent of structural and behavioural defences of target hosts and total parasitism by coevolved parasitoids (Gross 1991; Hawkins et al. 1993; Hochberg and Hawkins 1994), which has provided practitioners with a strong tool to judge the likelihood of success of a CBC project. A parallel approach has been the identification of factors that underpin success derived from the biological control record. There are inherent weaknesses in this approach (e.g. Hokkanen 1985) because $\mathrm{CBC}$ outcomes are closely tied to economic and political factors and not so much to the absolute impact of a CBC agent. As Cock et al. (2015) describe, implicitly or explicitly $\mathrm{CBC}$ is carried out to achieve specific societal goals, e.g. protecting livelihoods of smallholder farmers, reduce pesticide use, or protect biodiversity, whereas the outputs of CBC are often measured in terms to the reduction of the target pest population. Nonetheless, such analyses are useful as they complement the ecological approaches by providing useful insights into global trends in releases, establishments, outcomes and the broad factors that seem to influence success. A collation of the historical record also provides a crucial source of information about past projects against specific pests that practitioners can use in the design of new efforts against those pests (van Driesche and Bellows 1996).

BIOCAT is a database documenting all deliberate introductions of insects for the biological control of other insects since the 1890s. It was developed and compiled by the late David J. Greathead, former Director of the then International Institute of Biological Control (now integrated into CABI) with the help of his wife, Annette H. Greathead. In 1992, they provided a description of the database and overview analysis of the data (Greathead and Greathead 1992). After that, D. J. Greathead continued to update the database until his untimely death in 2006 (Murphy and Cock 2007). Thereafter, the database was neglected for some years until picked up by the present team. Unfortunately we do not have the definitive version of BIOCAT used for Greathead and Greathead (1992), only the updated live version that D.J. Greathead worked on. This prevents us from checking and recreating the numbers in Greathead and Greathead (1992) to confirm how they were derived.

There are no other published global collations and analyses of this type apart from those of introductions against weed targets (Winston et al. 2014) and nematodes and pathogens as BCAs (Hajek et al. 2005). The 1992 database has been used to assess benefits and risks of insect introductions (Greathead 1995), an updated but unpublished version - including records up to end 2001-was used in a historical overview of biological control in Africa (Greathead 2003), and the same or a different version was used to summarize the use of insect BCAs against insect pests in Hajek (2004). Unfortunately at the time of David Greathead's death, none of these versions of BIOCAT had been archived in such a way that we can now identify them.

The database has now been updated to include information from publications to the end of 2010, some fields have been restructured, and the nomenclature checked, especially for BCAs. In this, the first of a series of planned papers, an overview analysis is presented that compares our results of historical and country trends in introductions and outcomes with those of Greathead and Greathead (1992). In particular, the trends in these parameters post-1992 and new perspectives on the entire history that BIOCAT now covers are highlighted. Hereafter the two versions of the database are referred to as BIOCAT1992 and BIOCAT2010, and the latter will be archived as such. CABI plans to convert BIOCAT back to a relational database and make an interrogatable version available open access via the Plantwise knowledge bank (http:// www.plantwise.org/KnowledgeBank/home.aspx) in 2016.

\section{Materials and methods}

\section{Overview of the database}

The basic structure of BIOCAT2010 is the same as that described in Greathead and Greathead (1992) for BIOCAT1992, although this update was done in Microsoft Excel (2010), whereas BIOCAT1992 was in Ashton-Tate dBase IV. The main difference in database structure is that several of the original fields 
have been broken up into more fields to facilitate analysis. For example, the name of the BCA and principal target pest and their classifications, instead of being two fields for each, now comprise separate fields for genus, species, author, notes, order and family. The database fields of BIOCAT2010 are listed in appendix 1 , supplementary material.

The geographical nomenclature has also been changed using drop down menus, so that all political country units are now included with a partial breakdown of some countries into areas. In this paper we use 'region' to describe a group of countries or zoogeographical region, not for part of a country, which will be referred to as an 'area', which may be a state or equivalent, group of states, island, or island group. Thus, for example, USA is divided into mainland contiguous states, Alaska, Hawaii, and the various dependencies around the world. Similarly the UK comprises part of the British Isles, but the UK dependencies (Bermuda, St Helena, Ascension, etc.) appear as areas within the UK. In this way, it is now possible to analyse access to and provision of BCAs based on political units, e.g. to assess their relative contribution in the context of access and benefit sharing (Cock et al. 2010). Geopolitical changes have caused some problems, e.g. the sourcing or releasing of BCAs from or into what was then known as the USSR (we use the term 'former USSR'), Yugoslavia ('former Yugoslavia'), pre-independence India, etc. and as far as possible these have been updated to current political countries, but in some cases we have had to keep the old terms. Information on latitude and longitude has not been included, but would be easy to add at a later date based on the smallest geopolitical unit recognised for each source and introduction. In contrast, latitude and longitude for actual collection or release sites would be a much larger task dependent upon the quality of information originally reported.

Updating the database

This was done using the same approach as for BIOCAT1992: searches were made of published reviews of biological control introductions, $\mathrm{CAB}$ Abstracts and Biocontrol News and Information to locate all published information on new introductions of BCAs. Recent major reviews such as Waterhouse and Sands (2001) and Mason and Huber (2002) were particularly useful. The results fields of earlier introductions were updated when new information was found, but although searches were extensive this has not been comprehensive, so in some cases may still be out of date. It was necessary to interpret the published statements about impact into the simple categories developed by Greathead and Greathead (1992). We did not have the advantage of having just one person make these judgements (i.e. David Greathead in the 1992 paper), but the first two authors reviewed and occasionally adjusted the impact ratings used.

Over the years, scientific names and taxonomic classifications change. We set out to check and update the names of all BCAs and their target pests. Some groups were straightforward, and could be checked from authoritative on-line sources, of which the Taxapad databases for Ichneumonoidea (Yu et al. 2013) and Chalcidoidea (Noyes 2013) were particularly valuable. Other groups were updated from a variety of mostly internet sources such as EOL (2013) for many groups, Anichtchenko (2013) for Carabidae, Nedvěd and Kovár (2012) for genera of Coccinellidae, Beccaloni et al. (2003) for Lepidoptera, and Wharton and Yoder (2013) for parasitoids of Tephritidae.

The classification at family level has also changed since Greathead and Greathead (1992). We adjusted family classification to follow Sharkey (2007) for Hymenoptera, Bouchard et al. (2011) for Coleoptera, and van Nieukerken et al. (2011) for Lepidoptera. However, for practical reasons, we followed Greathead and Greathead (1992) in treating Aphidiinae as a family rather than a subfamily of Braconidae, to enable the aphid parasitoids to be analysed as a group. For other types of analysis it will be necessary to pool the two. In a future version of BIOCAT it might be preferable to add a field for subfamily for use when analysis is required at this level.

It was necessary to correct a small number of spelling mistakes from BIOCAT1992 that were detected, some of which have crept into other sources, e.g. CABI (2015). Consistency of spelling was further checked by sorting all names alphabetically and checking for inconsistencies such as misspellings and different adjectival gender agreements of specific names. We are aware that the International Code of Zoological Nomenclature requires that adjectival species names agree in gender with their genus (ICZN 1999), but have not considered it appropriate to do 
other than follow the standards set in the checklists and similar documentation we have followed, and we have not attempted to correct any adjectival species names ourselves on the basis of gender agreement. This means that Lepidoptera can be expected to follow the original spelling of the species description rather than show gender agreement, whereas most or all other groups will follow the gender agreement rule.

In addition to the extensive checking of species names and classification described above, several fields were sorted alphabetically in different combinations and checked for inconsistencies. One specific check examined all records where the same BCA was introduced into the same country from the same source country, but perhaps against different targets or on different dates. Most of these were checked against original sources and some tens of duplicate entries were detected and combined or deleted.

\section{Analysis of BIOCAT: summary statistics}

and trends in introductions, establishments, successes and country involvement.

Summary statistics were extracted and charts generated from the database using the Microsoft Excel (2010) functions. The mechanics are not described here, but for each table and chart, we set out precisely what was counted.

Overall summary statistics on introductions 1890-2010 were compiled to compare with those presented as Table 3 in Greathead and Greathead (1992). BIOCAT2010 was analysed in two ways: mode 1 , treating each unique combination of $\mathrm{BCA}$, target country and first year of introduction as one introduction (this was the approach in Greathead and Greathead 1992); and mode 2, treating each unique combination of BCA, source country, target country and first year of introduction as one introduction (the approach in Cock et al. 2010). Introducing different strains of the same species from different countries is usually done in the expectation that one strain may have a better climatic or ecological match and hence more effective in the target country, but may be for other reasons including adding genetic diversity to a laboratory colony or practical reasons, e.g. collections from several nearby populations in adjacent European countries, to obtain sufficient individuals for shipment. Interpreting the results of multiple strain introductions has been difficult in the past, but should be possible now using molecular methods. Generally counts for mode 2 will be slightly higher, as only a small proportion of introductions comprise multiple country sources. Mode 2 is clearly the appropriate approach to take when access and benefits sharing issues are to be considered. The derivation of each summary statistic is as follows:

1. The number of introductions is the total number of records.

2. The number of establishments was obtained by counting all records for 'Establishment' recorded as 'Permanent establishment'. Greathead and Greathead (1992) appear to have done this by discarding all 'Failed to become established' (F) and 'Result not known' $(\mathrm{N})$ results, and so included 'Temporary establishment' and 'Recovered (too soon to know if permanently established)'.

3. The number of pest target species was obtained as a count of each unique combination of 'Target genus' and 'Target species'. This will undercount those cases where releases were made against more than one target pest, and either a species listed as 'Target other' has not been a primary target, or a release was against a target identified as spp. (e.g. Spodoptera spp. [Lepidoptera: Noctuidae] which will only count as one target species). It will also undercount releases that were made against higher taxonomic groups, e.g. aphids, mealybugs. We do not know how Greathead and Greathead (1992) handled these relatively small numbers of cases.

4. The number of agent species was similarly obtained as a count of each unique combination of 'BCA genus' and 'BCA species'. Again this may undercount the true number of different BCAs where they are recorded as sp., spp., or the genus is unidentified. Again we do not know exactly how Greathead and Greathead (1992) handled this.

5. The number of countries and additional areas is actually the number of unique different combinations of 'Release country' and 'Release area'. The net result should be similar to the approach used by Greathead and Greathead (1992), although it does produce many ecological anomalies.

6. Number of countries. Greathead and Greathead (1992) did not consider the number of countries separately, but we counted the number of unique examples of 'Release country'.

7. This means that dependent territories of various types are included under their 'parent' country, 
the rationale being an expectation that these territories would follow similar sanitary and phytosanitary (WTO 1994) and access and benefit sharing procedures. These are counted by subtracting the number of countries from the number of countries and areas.

8. The number of successful BCA introductions is a count of those introductions where 'Impact' is rated 'Substantial control (other control needed occasionally or in small areas only)', 'Complete control (no other control required)' or 'Substantial to complete control (mixed opinions noted)'. This count has the drawback that a programme where control is attributed to two or more BCAs will count as two or more successful BCAs, whereas a single effective agent will only count as one.

9. To resolve this issue, within the subset of \#8, the number of successful programmes is the number of unique combinations of 'Target genus', 'Target species', 'Release country' and 'Release area'. We believe this is what Greathead and Greathead (1992) referred to as the number of different species controlled, as will be discussed below.

10. Within the subset of \#8, the number of different species controlled is the number of unique combinations of 'Target genus' and 'Target species'.

Historical trends in introductions were analysed by dividing the records up into decades based on the date of first introduction ('Date first year'). All records that had no date of introduction, or the information was too vague (e.g. 'before 1920'), were omitted, accounting for $5.6 \%$ of all records. The number of introductions per decade was plotted using both mode 1 and mode 2 .

Establishment and BCA success rates over time also used the data segregated by decades, and ignored all records with no date of introduction. For the analysis, each record was categorized as one of the following: not established (including 'Not known', 'Not established' and 'Temporary establishment'); established but no significant control ('Result unknown', 'Established but no control' and 'Partial control'); established and contributing to at least 'Substantial control'.

Next, we considered the number of unique successes based on the date of first introduction of a BCA that contributed to a substantial or complete control. Each target only counts once, i.e. repeat successes in other countries were not counted. Establishment and success rates over time also used the data segregated by decade, and ignored all records with no date of introduction. All records with impact less than substantial were then discarded. The remainder were sorted and the earliest for each combination of target genus and target species was kept and tabulated, i.e. 171 reported successes for which the year of first introduction is known.

Trends in country effort and successes were then analysed. For country effort, the number of introductions (mode 1) per decade was analysed for each country and grouped by decade of first introduction. As before, all records that had no date of introduction or the information was too vague were omitted. For country successes, as for the summary statistics, the number of successful BCAs is a count of those introductions where impact is rated substantial control or better. Mode 2 was used for this as normally there was no way of showing which BCA source country populations contributed to control. After discarding all records which were not successes, the remainder were categorized by decade and country. The small number of successes that had no date of introduction or for which the date was too vague were omitted.

\section{Results}

Overall summary statistics on results of introductions

For ease of comparison, the following results of the analysis of BIOCAT2010 reported here largely follow the format in Greathead and Greathead (1992). The summary of records in BIOCAT2010 compared to BIOCAT1992 is presented in Table 1. BIOCAT2010 contains information on 6158 introductions of BCAs, of which 2007 (32.6\%) have become established, leading to 620 satisfactory biological controls (10.1\% of introductions; $30.9 \%$ of established BCAs) against 172 different pests (29.3\% of those targeted). It can be seen that under mode 1 , the number of introductions, the number of BCAs established, the number of pest target species, the number of BCAs and the number of successful biological controls (i.e. at least satisfactory control) have risen quite substantially due to the 18 years of literature since BIOCAT1992. Thus introductions have risen by nearly $20 \%$, the number of targets by over $8 \%$, the number of agents employed 
Table 1 Summary of records included in BIOCAT, comparing the numbers from BIOCAT1992 (Greathead and Greathead 1992Table 3), with those obtained from BIOCAT2010

\begin{tabular}{|c|c|c|c|c|}
\hline & & BIOCAT1992 & $\begin{array}{l}\text { BIOCAT2010 } \\
\left(\text { Mode } 1^{\mathrm{a}}\right)\end{array}$ & $\begin{array}{l}\text { BIOCAT2010 } \\
\left(\text { Mode } 2^{b}\right)\end{array}$ \\
\hline 1 & No. of introductions (total records) & 4769 & 5715 & 6158 \\
\hline $2 \mathrm{a}$ & No. of establishments (excluding temporary) & $1434^{\mathrm{c}}$ & 1823 & 2007 \\
\hline $2 b$ & No. of establishments (including temporary) & 1445 & 1894 & 2084 \\
\hline 3 & No. of pest targets & 543 & 588 & \\
\hline 4 & No. of agent species & 2011 & 2384 & \\
\hline 5 & No. of countries and islands & 196 & 203 & \\
\hline 6 & No. of countries & & 148 & \\
\hline 7 & No. of additional islands & & 55 & \\
\hline 8 & No. of successful biological control agents & 517 & 620 & \\
\hline 9 & No. of successful programmes & & 440 & \\
\hline 10 & No. of different pest species controlled & 421 & 172 & \\
\hline
\end{tabular}

${ }^{a}$ Mode 1 each agent/target country/year is a separate introduction/establishment, e.g. an introduction of a biological control agent (BCA) from six countries counts as one introduction

b Mode 2 each source country/agent/target country/year is a separate introduction/establishment, e.g. an introduction of the same BCA from six countries counts as six introductions

c Greathead and Greathead (1992) did not include this statistic. It was extrapolated from BIOCAT2010 by removing records of temporary establishment of introductions from 1989 onwards where the source of information was published after 1992

by nearly $19 \%$, the number of establishments (excluding temporary) by over $27 \%$, and the number of satisfactory controls by $20 \%$. On the other hand, the total number of countries and areas implementing $\mathrm{CBC}$ has only risen marginally (just under $4 \%$ ). This table reveals one apparent difference in the results: Greathead and Greathead (1992) indicate from BIOCAT1992 that 421 different pest species were satisfactorily controlled, whereas we find from BIOCAT2010 that there are only 172 . However, we count the number of successful programmes as 440 , and so conclude that Greathead and Greathead (1992)'s figure of 421 actually refers to the number of successful programmes, not the number of different pest species satisfactorily controlled.

The statistics for mode 2 illustrate that post-1992 some CBC projects have used several source countries for a particular BCA and this has led to an increase in the number of establishments of BCAs overall (by $10 \%$ ). Unfortunately no figures are available for BIOCAT1992 for comparison. Some of the main features of the changes in the summary statistics from BIOCAT1992 to BIOCAT2010 are described in the following sections.
Historical trends in introductions, establishments and successes

The total number of introductions (for modes 1 and 2) made globally for each decade period plateaued in the 1950 s to the 1970 s, and has since been declining (Fig. 1). Some of the main factors that have probably influenced this trend are discussed later. Greathead and Greathead (1992) presented a similar figure (their Fig. 2a-mode 1 only), and underestimated the introductions for the 1980 s by about $20 \%$ due to the literature cut-off date. Similarly, since BIOCAT2010 is based on literature to the end of 2010, the number of introductions reported for the 2000s is likely to be underestimated, but we suggest this would be by no more than $25 \%$, i.e. the total for the 2000s may prove to be fewer than 200 .

The number of introductions when each country source is counted as a separate introduction (mode 2) is consistently slightly higher than when multiple source countries are treated as one (mode 1), but the overall pattern is the same using either mode (Fig. 1). Possibly it is significant that there is no difference in the totals introduced in the 2000 s, i.e. no introductions 


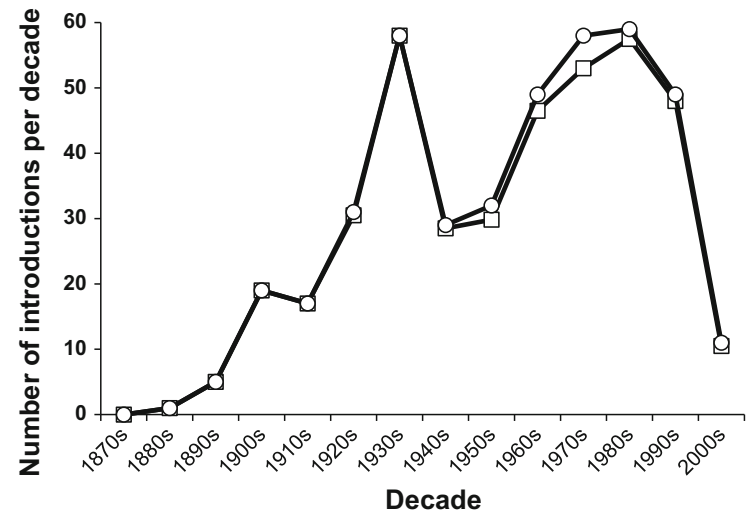

Fig. 1 The number of introductions of biological control agents each decade counted using mode 1 (squares) and mode 2 (circles)

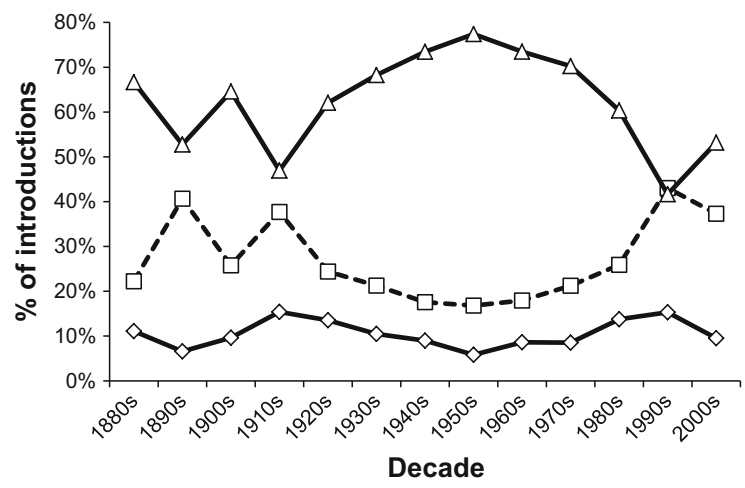

Fig. 2 Breakdown of introductions per decade to show the percentage that failed to become established (triangles), that became established but have not been shown to contribute to control (squares), and became established and contributed to successful biological control (circles). SE are $<1 \%$ except for the 1880 s where they are $<10 \%$

were made using the same BCA from more than one country.

In Fig. 2 the proportion of introductions each decade which fail to establish (including those with no report of establishment), establish but do not contribute to control (including those with no report of impact), and establish and contribute to successful control can be seen. As with the total introductions, some of the factors that may have influenced the pattern of proportions each decade are discussed later. However, setting aside the results for the 2000s (for which it is too early to expect full reporting), it is

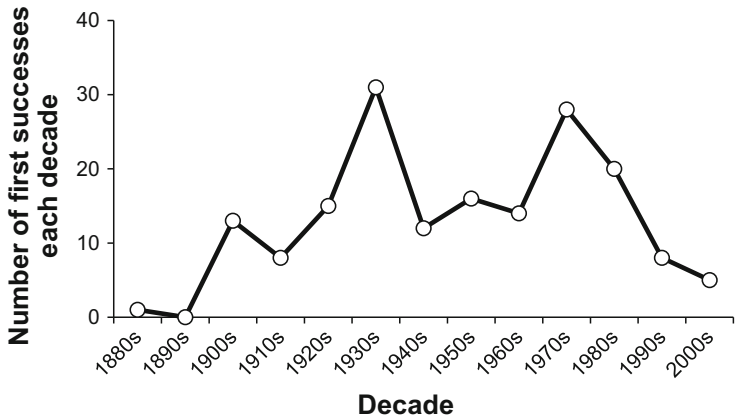

Fig. 3 The number of first successes each decade. Each target only counts once, i.e. repeat successes in other countries were not counted, and the decade is determined by the date when the successful biological control agent was introduced, not when success was achieved or reported

striking that from the 1950s to the 1990s there is a steady increase in both the percentage of introduced BCAs that become established and the percentage which are credited with contributing to a substantial control. In this regard the 1990 s were the most successful decade since the 1910s, and it is noteworthy that more than $50 \%$ of introductions led to establishment despite the overall decline in the total introductions (Fig. 1).

In Fig. 3 the number of first successes by decade is shown. Here each target only counts once and thus repeat successes are not included. Comparing Figs. 1 and 3, it can be seen that the decades in which the most successes first occurred (1930s and 1970s) do not align well with the number of releases each decade. The 1950s and 1960s had many releases, but relatively fewer new successes.

Trends in country effort and successes

To present these results, we focussed on those countries that made more than $40 \mathrm{CBC}$ releases in total and our analysis was based on the date of introduction (when known) over the total period 1870-2010 (Table 2). The results are consistent with Greathead and Greathead (1992) and show that to 2010, the USA was still the biggest user but Australia, Canada, the UK, New Zealand, Mauritius, Fiji, France, Israel and South Africa have also consistently invested considerable effort in BCA releases. However, the number of introductions by these countries declined in the 1980s and/or 1990s, particularly strongly in New 


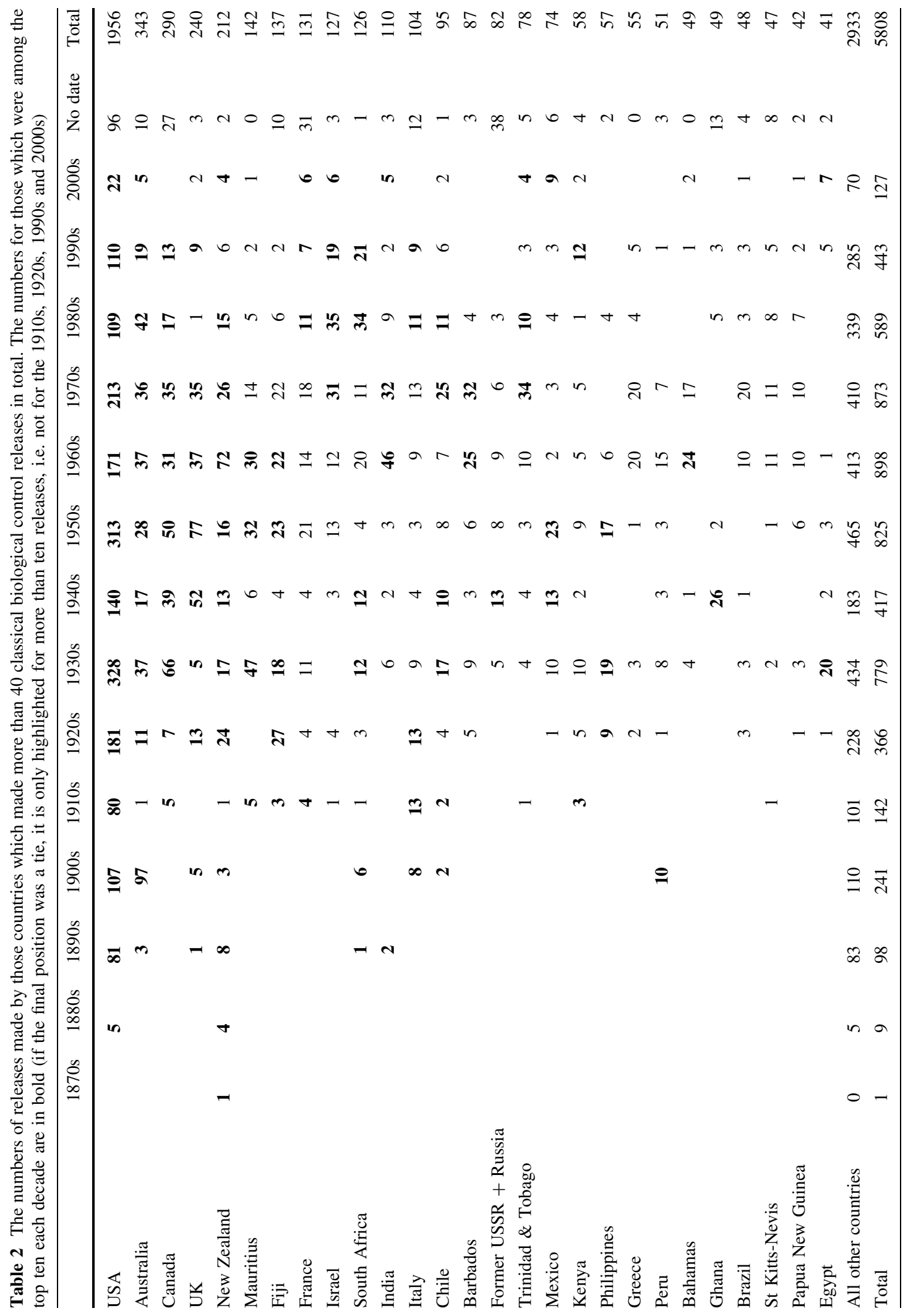




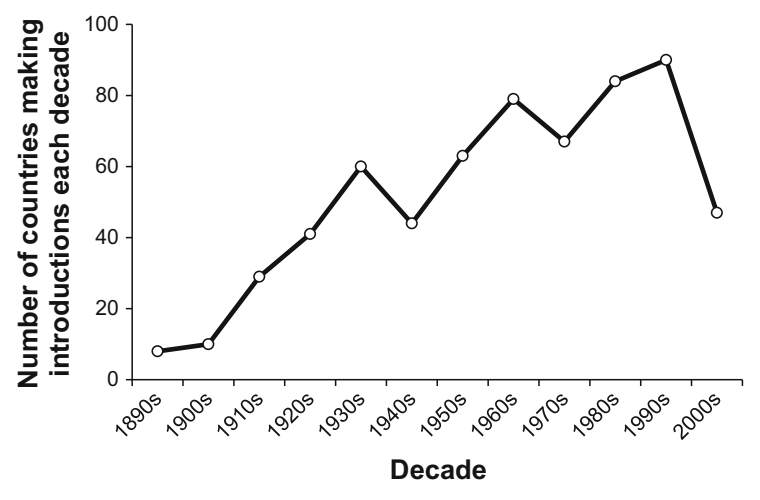

Fig. 4 The number of countries making classical biological control releases (any number of biological control agents) each decade

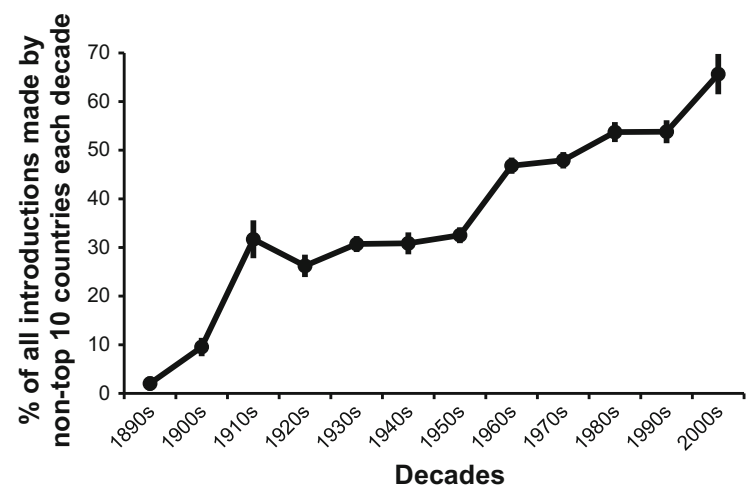

Fig. 5 The percentage (and SE) of releases each decade made by countries other than the top ten (which in total made the most releases)

Zealand, Mauritius and Fiji. Otherwise, the emphasis on $\mathrm{CBC}$ has fluctuated around the world but the number of countries making CBC introductions each decade has generally increased over time reaching 80 in the 1990s, again not including the likely incomplete records for the 2000s (Fig. 4). Similarly, the proportion of total releases each decade made by countries other than the ten countries that in total made the most releases has steadily increased, and these now account for more than half of all introductions (Fig. 5).

The trends in numbers of successful BCAs are fairly consistent between countries (Table 3), peaking in the 1930s and then at a plateau from the 1960s to 1990s. This table includes the 'top ten' (i.e. the ten countries that have reported the highest numbers of successful BCAs) and other countries as categories but here the top ten includes Italy, Chile and Spain, which have had relatively more successes than Mauritius, Fiji and Israel, which are among the top ten for number of releases (Table 1). Generally the number of countries reporting one or more successful biological control programmes each decade has been increasing (Fig. 6). At the moment it is not clear whether the 2000s represents a true drop, or a delay in evaluating and reporting successes. The proportion of all introductions of successful BCAs into countries other than the ten with the most introductions of successful BCAs has been generally increasing, and now more than half the introductions of successful BCAs are reported from these relatively less active countries (Fig. 7).

\section{Discussion}

It is important to recognize that many of the limitations of BIOCAT1992 remain with BIOCAT2010. Greathead and Greathead (1992) listed these as: the very uneven reporting of introductions between countries, the fact that researchers are likely to publish successes rather than failures, and that subsequent observations have not supported initial assessments. These categories are, of course, not always mutually exclusive. Reporting remains uneven. One cause may be a lack of agreed reporting standards or peerreviewed outlets for simple reports of the release or establishment of a BCA. The fields used in the BIOCAT database offer insight into minimum reporting requirements: What was released? Where did it come from (immediately and originally if different)? Where was it released (preferably with information of numbers of releases and numbers of individuals)? When was it released? Why was it released? Where was the BCA recovered? At what level of incidence? How long after releases were last made? What other published or unpublished documentation is available relating to this release and recovery? A common cause for uneven reporting is that, in general, less information is available for nationally funded projects or parts of projects (usually the monitoring and evaluation phase) in developing countries largely because of either lack of human resources or lack of the necessary skills to record and process relevant data on results of impact of a BCA. For example, introductions of parasitoids for trial against the coffee berry borer, Hypothenemus hampei (Ferrari) (Coleoptera: 
Table 3 The number of successful biological control agents (BCAs) by decade reported for the ten countries reporting the largest number of successful BCAs and 'others'. Note this includes repeat successes in multiple countries and is not the same as the ten countries that made the most releases

\begin{tabular}{|c|c|c|c|c|c|c|c|c|c|c|c|c|}
\hline & USA & Australia & France & UK & Italy & New Zealand & Chile & Canada & Spain & South Africa & Other countries & Total \\
\hline $1890 \mathrm{~s}$ & 5 & & & & & 1 & & & & 1 & 2 & 9 \\
\hline $1900 \mathrm{~s}$ & 12 & 10 & & 1 & 2 & 1 & 1 & & & 2 & 5 & 34 \\
\hline $1910 \mathrm{~s}$ & 13 & & 3 & & 1 & & 1 & & 1 & & 14 & 33 \\
\hline $1920 \mathrm{~s}$ & 20 & 1 & 3 & 6 & 3 & 4 & 2 & 1 & 5 & 2 & 24 & 71 \\
\hline $1930 \mathrm{~s}$ & 30 & 7 & 1 & & 3 & 3 & 7 & 9 & & & 44 & 104 \\
\hline $1940 \mathrm{~s}$ & 10 & 7 & & 1 & & 1 & 3 & 1 & 1 & & 29 & 53 \\
\hline $1950 \mathrm{~s}$ & 22 & 4 & 5 & 7 & & 2 & 1 & 1 & 1 & 1 & 32 & 76 \\
\hline $1960 \mathrm{~s}$ & 22 & 10 & & 3 & 2 & 3 & 4 & 3 & 3 & 5 & 56 & 111 \\
\hline 1970s & 24 & 8 & 7 & 3 & 6 & 4 & 2 & 5 & 7 & & 46 & 112 \\
\hline $1980 \mathrm{~s}$ & 25 & 7 & 2 & 1 & 8 & 2 & 1 & 1 & & 2 & 53 & 102 \\
\hline $1990 \mathrm{~s}$ & 18 & 10 & 3 & 4 & 1 & 3 & 1 & 1 & 2 & 5 & 61 & 109 \\
\hline $2000 \mathrm{~s}$ & 5 & 3 & 4 & & & 1 & 1 & & & & 22 & 36 \\
\hline Total & 206 & 67 & 28 & 26 & 26 & 25 & 24 & 22 & 20 & 18 & 388 & 850 \\
\hline
\end{tabular}

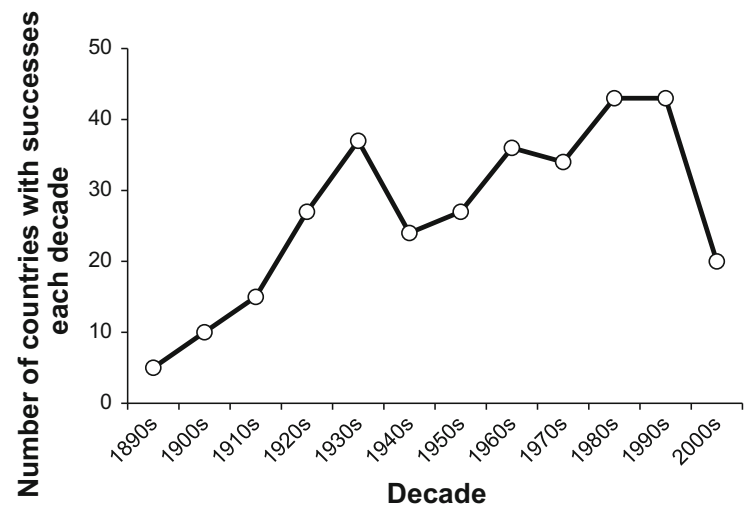

Fig. 6 The number of countries for which a successful biological control agent was reported each decade (allocated on the basis of when the biological control agent was released, not when the success happened or was reported)

Curculionidae), have been made in several major coffee growing developing countries across the globe stretching over several decades (Baker et al. 2002) but the results of these are still unclear in several cases. In addition, we suggest that where the outcome is not clear-cut, e.g. control is partial or only effective in certain areas or under certain conditions, it is likely that these cases will not be fully investigated and documented, or will be simplified in reports. Greathead and Greathead (1992) also mention the lack of information from Latin American countries and this still remains probably because of the major language

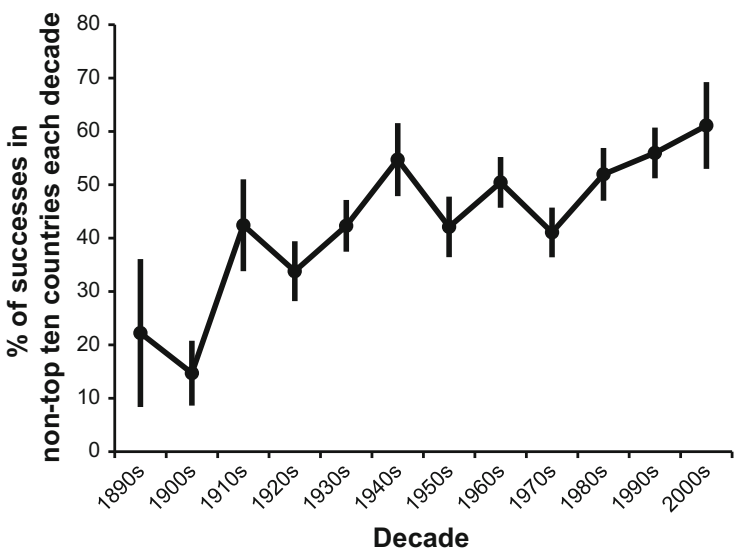

Fig. 7 The percentage (and SE) of successful biological control agents released each decade by countries other than the top ten (which in total had the most successes, not that made the most releases). The date is based on when the biological control agent was released, not when the success happened or was reported

divide as most international outlets for biological control reporting lie in English language journals. The recent book by Bettiol et al. (2014) will help to address this, but was too recent to include in our update. There are no specific data to support the suggestion that successes are more likely to be published than failures but it seems a reasonable assumption, and it is known that in several biological projects the full outcomes are not known for all the agents released. As one example 
of many for this last point, much effort has been made by some countries in the $\mathrm{CBC}$ of invasive Liriomyza spp. leaf miners (Diptera: Agromyzidae) of vegetable crops and while complete control has been reported in several cases and a dominant parasitoid highlighted, the data in BIOCAT2010 suggest that the outcome of approximately $30 \%$ of the individual released agents is unknown. The tendency to overstate impact also persists. For example, in reviewing new data for BIOCAT2010, based on their personal field experience, the current authors found several examples of what were likely to be 'overstated' results. Initial results following a release may look spectacular in the short term and be reported as such, but in the longer term population dynamics or crop management practices may allow occasional pest outbreaks and damage to continue, for example due to pest resurgence following pesticide applications to control another pest.

In addition to the limitations in the nature of the available data on CBC introductions and outcomes, there have been difficulties in confirming the identity and taxonomic status of some BCA species. We have noted some of the most useful resources for namechecking in the methods section. Additional groups where an authoritative global checklist would have been especially useful include Coccinellidae, Tachinidae, Scoliidae and Tiphiidae.

While the total number of introductions has been falling since the 1970s (Fig. 1), comparing the overall statistics in BIOCAT2010 with BIOCAT1992 shows that the total introductions have risen by $20 \%$ in that 18 year period compared to the total for the 112 years 1880-1992. Much of this growth is attributable to projects in countries without a long history of biological control (Fig. 5). We believe this indicates that $\mathrm{CBC}$ has remained a core activity of pest management for many national programmes. Unfortunately, the number of different pests controlled in the period 1880-1992 given in Greathead and Greathead (1992) is in error and somewhat surprisingly, no one seems to have challenged this number in the interim, although the real figure (172) is well under half of that reported earlier (421). Our figure for the number of unique pests controlled also broadly agrees with the analysis of DeBach and Rosen (1991) where, using records up to 1991, they estimate the species of insect pests being permanently controlled by introduced natural enemies to be 164. Most of the pests controlled are major invasive species that have affected the agricultural economies of countries and in some cases wider regions. Thus to date the collective effort in $\mathrm{CBC}$ has stemmed the loss of millions of dollars in crop losses across the globe, protecting livelihoods and alleviating poverty (Cock et al. 2015; DeBach 1964; Greathead 1995; Gurr and Wratten 2000; Hill and Greathead 2000; Lubulwa and McMeniman 1997; Norgaard 1988).

Our analysis shows that up to 2010, the ten countries that invested the most in BCA releases (Table 2) remain the same as those highlighted in Greathead and Greathead (1992). The USA has been the largest user accounting for $32 \%$ of all introductions. Over the last two decades, several of these 'traditional big user countries' have cut back, but in contrast there is a marked increase over time in the number of countries making one or more introductions (Figs. 4, 5), from fewer than ten in the 1890s to 90 in the 1990s with the only substantial drop in the 1940s which would have been due to the impact of World War II. The number of countries reporting successes has generally increased over time (Fig. 6) and the current analysis shows that the top ten countries for successes (Table 3) differs from the top ten users (Table 2) with Italy, Chile and Spain replacing Mauritius, Fiji and Israel. In an analysis of BIOCAT data, Hajek (2004) shows that successful outcomes increase in relation to the number of agents introduced but reach a plateau at 9-14 agents. Thus, over time, $\mathrm{CBC}$ has become a tool in use across the globe, and no longer concentrated in a few countries, although its development has progressed at different times and different rates between countries as noted earlier by Huffaker and Messenger (1976). For example, France has been continuously active since the 1950s. Mauritius and Fiji were most active from the 1920s to the 1970s but introductions have now dropped off to almost nothing. Activity in both countries reflects investment during the colonial period, followed by a period of strong partnership with CABI (Greathead 1971; Rao 1971). India and Barbados were particularly active in the 1960s and 1970s, which reflects partnership with CABI for the former (Rao et al. 1971) and with $\mathrm{CABI}$ and the Caribbean Agricultural Research and Development Institute for the latter (Cock 1985). Either CBC activity in the countries of the former USSR was poorly documented, at least with regard to dates, or we have failed to identify, access 
and interpret relevant literature. Interestingly countries other than the top ten users overall form an increasing proportion of the successes (Fig. 7). This pattern in country effort may be down to several reasons but one factor is likely to be the investment made by funding agencies in the 1970s through to the 1990s to support CBC and CBC capacity building in the developing world. Another factor has been the development of international guidelines for the safe introduction of BCAs (IPPC 1996, 2005), which has given countries new to CBC the confidence to proceed safely with this approach (Kairo et al. 2003).

Nonetheless, despite the increase in country effort, the trend in total introductions (Fig. 1) since the 1970s does seem to be in decline as even assuming an adjusted figure for the 2000s (using a weighting based on the BIOCAT1992 figures for the 1980s versus the final outcome), the total number will only be a half of that for the 1990s. This could be seen as doing CBC better, as the trend is counterbalanced by an increasing proportion of establishments and successes each decade since the 1970s. These patterns are likely to be due to several and interrelated reasons and some of these have been discussed by other authors (e.g. Greathead 2003) but first it is important to understand and set the context by looking at the history of CBC and the changing global views on the environment.

Various factors have been known, or at least suggested to influence the level of activity in CBC since the 1880s when the approach (as now defined) first began to be used. The period 1880-1950 was characterized by a general increase in effort by an increasing number of countries following the early major successes in the USA with cottony cushion scale (Icerya purchasi Maskell, Hemiptera: Monophlebidae) and then others in Europe (Clausen 1978; Greathead 1976; Huffaker and Messenger 1976) but during the two World Wars effort reduced for obvious reasons. The approach to CBC was largely empirical during this period but as the proportion of establishments and successes slowly declined from the 1910s to the 1940s (Fig. 2) many practitioners wanted CBC to be more predictable and thus an interest in theory took root. Unfortunately, this did not improve matters and, as Greathead and Greathead (1992) noted, in the 1950s and 1960s there was surge in the total number of introductions (Fig. 1) but this increased effort led to even fewer successes in the 1950s and the situation only improved marginally in the 1960s. During this period, many of the projects were often small and poorly resourced, so that pre-introduction studies tended to be more restricted in scope and detail. First successes were also particularly low during these decades (Fig. 3). The fact that the number of introductions of a BCA for a particular target from more than one country (mode 2) rises during this decade (although this was also high in the 1930s-Fig. 1) gives some credence to Greathead and Greathead's (1992) statement that 'many practitioners began to introduce all available natural enemies considered to have even the remotest chance of success with little care or detailed study of their host relations or ecological requirements'. It may be that during the 1940 s to 1960 s there was relatively little research on new BCAs, due to different priorities during World War II followed by the prioritization of work on chemical pesticides expected to solve all pest problems.

Events took a different turn from about the 1970s with additional factors guiding approaches to BCA introductions by countries but the magnitude of each has been changing, resulting in the pattern we see emerging in the 2000s. A notable change was the general increase in the effort in research to understand the ecology and host relations of BCAs in more depth. Greathead and Greathead (1992) argue convincingly that this trend led to more establishments and successes as seen from the 1970s onwards and they cite the increase in research on the BCAs to improve tropical cereal stem borer control as an example. The rise in the proportion of successes of total introductions (Fig. 2) and the general increase in the number of countries reporting successes (Fig. 6) from the 1970s along with the first successes in the 1970s (Fig. 3) also support this explanation. Working against this though has been a growing risk-averse culture for $\mathrm{CBC}$ in many countries, including several of the largest user countries, which has also affected weed biological control (Moran and Hoffmann 2015). The overall impact has been the need for more in-depth testing of BCAs to include the risk of non-target and environmental impact (Bigler et al. 2006), which in turn has led to a rise in the cost and time needed for CBC programmes. One specific consequence of this may be that countries are now less keen to try new targets as reflected in the decline in first successes since the 1970s which does seem to correlate with the decline in number of releases in the same period. It may also 
explain the observation that the mode 1 and mode 2 statistics are currently the same for the 2000s (see Fig. 1). This may reflect a more stringent approach to risk assessment: if each population has to be studied and evaluated separately, it would be more efficient to work with just one population.

The rise in risk aversion across the globe seems to stem from greater environmental awareness that has developed since the 1992 Rio conference on the environment and the resultant Convention on Biological Diversity (CBD 1993) because this provided a framework for a greater focus on issues including the concept of 'invasive alien species' and, in particular, the negative impacts that these can have in natural environments as well as agriculture. This then provided a platform for general ecologists to assess a wide range of impacts of invasive alien species which included studies on BCAs and non-target impacts. Much has been made of a few cases but the relevant point here is that an extensive review of non-target impacts of insect BCAs showed that these have rarely occurred and in the few cases where they have, impacts are minor (Greathead 1995; Lynch and Thomas 2000; Parry 2008; Kenis et al. 2009).

A more recent event that is affecting the practice of $\mathrm{CBC}$ is the ratification of the Nagoya Protocol (CBD 2011) in October 2014 and the on-going formalization of access and benefit sharing provision by the signatories. Depending on how each country implements legislation to manage access to their genetic resources, the ability of the international biological control community to access potential BCAs may decrease, or efforts may focus on those source countries that have appropriate functioning regulations. In the short term, the lack of appropriate regulations and inexperience of both practitioners and regulators are likely to cause significant delays and blocks. This has already had some impact, causing delays in some $\mathrm{CBC}$ programmes and reducing the options available to study potential BCAs in others (Cock et al. 2010; van Lenteren et al. 2011). However, as we have shown, many more countries have been implementing CBC in recent years, and it is to be hoped that enlightened national interest will facilitate continuing with the long-established practice of free multi-lateral exchange of BCAs.

In conclusion, while the number of introductions has been decreasing each decade since the 1970s, several positive trends have been identified over the same period: a higher proportion of introductions have become established and contributed to the successful control of target pests, and the number of countries implementing $\mathrm{CBC}$ continues to increase quite markedly. These positive trends most likely reflect the greater research effort now made to optimize the chance of a successful outcome and increased confidence in $\mathrm{CBC}$ as a viable pest management strategy. These trends may also help counter the current issues of risk aversion and the impact of access and benefit sharing on the practice of $\mathrm{CBC}$.

Acknowledgments In updating BIOCAT and preparing this review, all authors except Francis were involved in refining the structure of the database. Kairo and Francis led on the collection of New World updates, R. Murphy led on the collection of Old World updates, Thompson managed the BIOCAT database and its updating, Cock and Thompson made the quality checks, Cock carried out the analyses and Cock and S Murphy led on the writing. We thank Annette Greathead for kindly providing the BIOCAT database updated to 2005 from the late David Greathead's files. We acknowledge with thanks the support of the CABI Development Fund (supported by contributions from the Australian Centre for International Agricultural Research, the UK's Department for International Development, the Swiss Agency for Development and Cooperation and others), the International Organization for Biological Control, and U.S. Department of Agriculture, Animal and Plant Health Inspection Service Grant 10-8100-0755-CA to Kairo while at the Center for Biological Control, Florida A\&M University.

Open Access This article is distributed under the terms of the Creative Commons Attribution 4.0 International License (http:// creativecommons.org/licenses/by/4.0/), which permits unrestricted use, distribution, and reproduction in any medium, provided you give appropriate credit to the original author(s) and the source, provide a link to the Creative Commons license, and indicate if changes were made.

\section{References}

Anichtchenko A (coordinator) (2013) Carabidae of the world. http://carabidae.org/. Accessed 7 Oct 2015

Baker PS, Jackson JAF, Murphy ST (2002) Natural enemies, natural allies. Feriva, Cali

Bebber DP, Holmes T, Gurr SJ (2014) The global spread of crop pests and pathogens. Glob Ecol Biogeogr 23:1398-1407

Beccaloni G, Scoble M, Kitching I, Simonsen T, Robinson G, Pitkin B, Hine A, Lyal C (eds) (2003) The global Lepidoptera names index (LepIndex). http://www.nhm.ac.uk/ our-science/data/lepindex/. Accessed 7 Oct 2015

Bettiol W, Rivera MC, Mondino P, Montealegre AJR, Colmenárez YC (eds) (2014) Control biológico de enfermedades de plantas en América Latina y el Caribe. Facultad de Agricultura, Universidad de la República, Montevideo 
Bigler F, Babendreier D, Kuhlmann U (eds) (2006) Environmental impact of invertebrates for biological control of arthropods: methods and risk assessment. CABI, Wallingford

Bouchard P, Bousquet Y, Davies AE, Alonso-Zarazaga MA, Lawrence JF, Lyal CHC, Newton AF, Reid CAM, Schmitt M, Ślipiński SA, Smith ABT (2011) Family-group names in Coleoptera (Insecta). ZooKeys 88:1-972

CABI (CAB International) (2015) Crop protection compendium. CABI, Wallingford. http://www.cabi.org/cpc. Accessed 7 Oct 2015

CBD (Convention on Biological Diversity) (1993) Convention on Biological Diversity (with annexes). Concluded at Rio de Janeiro on 5 June 1992. U. N.-Treaty Ser 1760(30619): 142-382

CBD (Convention on Biological Diversity) (2011) Nagoya Protocol on access to genetic resources and the fair and equitable sharing of benefits arising from their utilization to the Convention on Biological Diversity: text and annex. Secretariat of the Convention on Biological Diversity, Montreal

Clausen CP (ed) (1978) Introduced parasites and predators of arthropod pests and weeds: a world review. Agricultural Handbook No. 480. United States Department of Agriculture, Washington, DC

Cock MJW (ed) (1985) A review of biological control of pests in the Commonwealth Caribbean and Bermuda up to 1982. Technical Communication No. 9, Commonwealth Institute of Biological Control. Commonwealth Agricultural Bureaux, Farnham Royal

Cock MJW, van Lenteren JC, Brodeur J, Barratt BIP, Bigler F, Bolckmans K, Cônsoli FL, Haas F, Mason PG, Parra JRP (2010) Do new access and benefit sharing procedures under the Convention on Biological Diversity threaten the future of biological control? BioControl 55:199-218

Cock MJW, Day RK, Hinz HL, Pollard KM, Thomas SE, Williams FE, Witt ABR, Shaw RH (2015) The impacts of some classical biological control successes. CAB Rev 10(42):1-58

DeBach P (ed) (1964) Biological control of insect pests and weeds. Chapman \& Hall, London

DeBach P, Rosen D (1991) Biological control by natural enemies, 2nd edn. Cambridge University Press, Cambridge

EOL (Encyclopedia of Life) (2013) Encyclopedia of life. http:// eol.org/. Accessed 7 Oct 2015

Greathead DJ (1971) A review of biological control in the Ethiopian Region. Technical Communication No. 5, Commonwealth Institute of Biological Control. Commonwealth Agricultural Bureaux, Farnham Royal

Greathead DJ (ed) (1976) A review of biological control in western and southern Europe. Technical Communication No. 7, Commonwealth Institute of Biological Control. Commonwealth Agricultural Bureaux, Farnham Royal

Greathead DJ (1995) Benefits and risks of classical biological control. In: Hokkanen HMT, Lynch JM (eds) Biological control: benefits and risks. Cambridge University Press, Cambridge, pp 53-63

Greathead DJ (2003) Historical overview of biological control in Africa. In: Neuenschwander P, Borgemeister C, Langewald $\mathbf{J}$ (eds) Biological control in IPM systems in Africa. CABI, Wallingford, pp 1-26
Greathead DJ, Greathead AH (1992) Biological control of insect pests by insect parasitoids and predators: the BIOCAT database. Biocontrol News Inf 13:61N-68N

Gross P (1991) Influence of target pest feeding niche on success rates in classical biological control. Environ Entomol 20:1217-1227

Gurr G, Wratten S (eds) (2000) Biological control: measures of success. Kluwer, Dordrecht

Hajek AE (2004) Natural enemies: an introduction to biological control. Cambridge University Press, Cambridge

Hajek AE, McManus ML, Delalibera Jr I (2005) Catalogue of introductions of pathogens and nematodes for classical biological control of insects and mites. FHTET-2005-05. Forest Health Technology Enterprise Team, Morgantown

Hawkins BA, Thomas MB, Hochberg ME (1993) Refuge theory and biological control. Science 262:1429-1432

Hill G, Greathead D (2000) Economic evaluation in classical biological control. In: Perrings C, Williamson M, Dalmazzone $\mathrm{S}$ (eds) The economics of biological invasions. Edward Elgar Publishing, Cheltenham, pp 208-223

Hochberg ME, Hawkins BA (1994) The implications of population dynamics theory to parasitoid diversity and biological control. In: Hawkins BA, Sheehan W (eds) Parasitoid community ecology. Oxford Science Publications, Oxford, pp 451-471

Hokkanen H (1985) Success in classical biological control. CRC Crit Rev Plant Sci 3:35-72

Huffaker CB, Messenger PS (eds) (1976) Theory and practice of biological control. Academic Press, New York

ICZN (International Commission on Zoological Nomenclature) (1999) International Code of Zoological Nomenclature, 4th edn. International Trust for Zoological Nomenclature, London. http://iczn.org/iczn/index.jsp. Accessed 7 Oct 2015

IPPC (International Plant Protection Convention) (1996) Code of conduct for the import and release of exotic biological control agents. International Standards for Phytosanitary Measures No. 3. Food and Agriculture Organization of the United Nations, Rome

IPPC (International Plant Protection Convention) (2005) Guidelines for the export, shipment, import and release of biological control agents and other beneficial organisms. International Standards for Phytosanitary Measures No. 3. Food and Agriculture Organization of the United Nations, Rome

Kairo MTK, Cock MJW, Quinlan MM (2003) An assessment of the use of the code of conduct for the import and release of exotic biological control agents (ISPM no. 3) since its endorsement as an international standard. Biocontrol News Inf 24:15N-27N

Kenis M, Auger-Rozenberg M-A, Roques A, Timms L, Péré C, Cock MJW, Settele J, Augustin S, Lopez-Vaamonde C (2009) Ecological effects of invasive alien insects. Biol Invasions 11:21-45

Lubulwa G, McMeniman S (1997) An economic evaluation of realised and potential impacts of 15 of ACIAR's biological control projects (1983-1996). ACIAR Economic Evaluation Unit, Working paper series 26. Australian Centre for International Agricultural Research, Canberra

Lynch LD, Thomas MB (2000) Nontarget effects in the biocontrol of insects with insects, nematodes and microbial 
agents: the evidence. Biocontrol News Inf 21(4):117N$130 \mathrm{~N}$

Mason PG, Huber JT (2002) Biological control programmes in Canada, 1981-2000. CABI, Wallingford

Moran VC, Hoffmann JH (2015) The fourteen International Symposia on Biological Control of Weeds, 1969-2014: delegates, demographics and inferences from the debate on non-target effects. Biol Control 87:23-31

Murphy RJ, Cock MJW (2007) David Greathead: a life in biological control. Biocontrol News Inf $28: 1 \mathrm{~N}-9 \mathrm{~N}$

Nedvěd O, Kováŕ I (2012) Appendix: list of genera in tribes and subfamilies. In: Hodek I, Honěk A, van Emden HF (eds) Ecology and behaviour of the ladybird beetles (Coccinellidae). Wiley, Oxford, pp 526-531. Updated version: http:// zoo.prf.jcu.cz/index.php/component/content/article/48-vyz kumy/1482-list-of-genera-of-coccinellidae.html. Accessed 7 Oct 2015

Norgaard RB (1988) The biological control of cassava mealybug in Africa. Am J Agric Econ 70:366-371

Noyes JS (2013) Interactive catalogue of world Chalcidoidea 2001. http://www.ichneumonoidea.name/taxapadmain.php. Accessed 7 Oct 2015

Parry D (2008) Beyond Pandora's box: quantitatively evaluating non-target effects of parasitoids in classical biological control. Biol Invasions 11:47-58

Rao VP (1971) Biological control of pests in Fiji. Miscellaneous Publication No. 2, Commonwealth Institute of Biological Control. Commonwealth Agricultural Bureaux, Farnham Royal

Rao VP, Ghani MA, Sankaran T, Mathur KC (1971) A review of the biological control of insects and other pests in southeast Asia and the Pacific region. Technical Communication No. 6, Commonwealth Institute of Biological Control. Commonwealth Agricultural Bureaux, Farnham Royal

Sharkey MJ (2007) Phylogeny and classification of Hymenoptera. Zootaxa 1668:521-548

van Driesche RG, Bellows TR Jr (1996) Biological control. Chapman \& Hall, New York

van Lenteren JC, Cock MJW, Brodeur J, Barratt BIP, Bigler F, Bolckmans K, Haas F, Mason PG, Parra JRP (2011) Will the Convention on Biological Diversity put an end to biological control? Rev Bras Entomol 55:1-5

van Nieukerken EJ, Kaila L, Kitching IJ, Kristensen NP, Lees DC, Minet J, Mitter C, Mutanen M, Regier JC, Simonsen TJ, Wahlberg N, Yen S-H, Zahiri R, Adamski D, Baixeras J, Bartsch D, Bengtsson BA, Brown JW, Bucheli SR, Davis DR, De Prins J, De Prins W, Epstein ME, Gentili-Poole P, Gielis C, Hättenschwiler P, Hausmann A, Holloway JD, Kallies A, Karsholt O, Kawahara AY, Koster S, Kozlov MV, Lafontaine JD, Lamas G, Landry J-F, Lee S, Nuss M, Park K-T, Penz C, Rota J, Schintlmeister A, Schmidt BC, Sohn J-C, Solis MA, Tarmann GM, Warren AD, Weller S, Yakovlev RV, Zolotuhin VV, Zwick A (2011) Order
Lepidoptera Linnaeus, 1758. In: Zhang Z-Q (ed) Animal biodiversity: an outline of higher-level classification and survey of taxonomic richness. Zootaxa 3148:212-221

Waterhouse DF, Sands DPA (2001) Classical biological control of arthropods in Australia. ACIAR Monograph No. 77. Australian Centre for International Agricultural Research, Canberra

Wharton RA, Yoder MJ (2013) Parasitoids of fruit-infesting Tephritidae. http://paroffit.org. Accessed 7 Oct 2015

Winston RL, Schwarzländer M, Hinz HL, Day MD, Cock MJW, Julien MH (eds) (2014) Biological control of weeds: a world catalogue of agents and their target weeds, 5th edn. FHTET-2014-04. USDA Forest Service, Forest Health Technology Enterprise Team, Morgantown

WTO (World Trade Organization) (1994) The Sanitary and Phytosanitary Agreement. http://www.wto.org/english/docs_ e/legal_e/legal_e.htm\#sanitary. Accessed 7 Oct 2015

Yu DSK, van Achterberg C, Horstmann K (2013) World Ichneumonoidea 2011. Taxonomy, biology, morphology and distribution. http://www.ichneumonoidea.name/taxapadm ain.php. Accessed 7 Oct 2015

Matthew Cock is CABI's chief scientist and an honorary member of the International Organisation for Biological Control.

Sean Murphy studies the biology of insect and plant populations, factors generating outbreaks, and the development of management with a focus on prevention, IPM and biological control.

Moses Kairo is professor of entomology and dean in the School of Agricultural and Natural Sciences, University of Maryland Eastern Shore. His research interests encompass policy and implementation of biological control and invasive species management.

Emma Thompson is a researcher at CABI working on arthropod biological control using entomopathogenic fungi and parasitoids.

Rebecca Murphy has been an editor for over three decades, working on a wide range of publications in many fields of applied biology. She has edited the news section of Biocontrol News and Information for CABI since 1997.

Antonio Francis is with the Florida Department of Agriculture and Consumer Services, Division of Plant Industry. His research interests include biological control, pest monitoring and detection, and integrated pest management of invasive insect species. 